\title{
Supporting Decision-Makers: An Expanded Framework
}

\author{
Daniel J. Power \\ University of Northern lowa, USA
}

\author{
power@uni.edu
}

\begin{abstract}
A conceptual framework for Decision Support Systems (DSS) is developed based on the dominant technology component or driver of decision support, the targeted users, the specific purpose of the system and the primary deployment technology. Five generic categories based on the dominant technology component are proposed, including Communications-Driven, Data-Driven, Document-Driven, Knowledge-Driven, and Model-Driven Decision Support Systems. Each generic DSS can be targeted to internal or external stakeholders. DSS can have specific or very general purposes. Finally, the DSS deployment technology may be a mainframe computer, a client/server LAN, or a Web-Based architecture. The goal in proposing this expanded DSS framework is to help people understand how to integrate, evaluate and select appropriate means for supporting and informing decision-makers.
\end{abstract}

Keywords: Decision Support, frameworks, DSS, decision-makers.

\section{Introduction}

Decision-makers receive and analyze information using many different media, including traditional print, group and interpersonal information exchanges, and computerbased tools. One set of computer-based tools has been termed Decision Support Systems. For more than 30 years, researchers and Information Systems specialists have built and studied a wide variety of systems for supporting and informing decision-makers that they have called Decision Support Systems or Management Decision Systems (cf., Scott Morton, 1971).

In the past few years, some additional terms like business intelligence, data mining, on-line analytical processing, groupware, knowledgeware, and knowledge management have been used for systems that are intended to inform and support decision-makers. The new terms are imprecisely defined and subject to marketing hyperbole. This proliferation of terms creates problems in conducting research and in communicating with decision-makers about deci-

Material published as part of this proceedings, either on-line or in print, is copyrighted by the author with permission granted to the publisher of Informing Science for this printing. Permission to make digital or paper copy of part or all of these works for personal or classroom use is granted without fee provided that the copies are not made or distributed for profit or commercial advantage AND that copies 1) bear this notice in full and 2) give the full citation on the first page. It is permissible to abstract these works so long as credit is given. To copy in all other cases or to republish or to post on a server or to redistribute to lists requires specific permission from the author. sion support systems. The solution is developing an expanded and well-defined framework for categorizing decision support systems.

The terms framework, taxonomy, conceptual model and typology are often used interchangeably. Taxonomies classify objects and typologies show how mutually exclusive types of things are related. Frameworks provide an organizing approach and a conceptual model shows how ideas are related. The general desire is to create a set of labels that help people organize and categorize information. Sprague and Watson (1996) argue typologies, frameworks or conceptual models are "often crucial to the understanding of a new or complex subject." Decision support is not a new subject, but it is complex and evolving. A good framework shows the parts of a topic and how the parts interrelate.

Sprague and Carlson (1982) and others define Decision Support Systems broadly as interactive computer based systems that help decision-makers use data and models to solve ill-structured, unstructured or semi-structured problems. Bonczek, Holsapple and Whinston (1981) argued the "system must possess an interactive query facility, with a query language that ... is ... easy to learn and use (p. 19)". Various types of DSS help decision-makers use and manipulate very large databases; some help managers apply checklists and rules; others make extensive use of mathematical models (cf., Power, 1997). 


\section{Supporting Decision-Makers}

This article is an attempt to briefly summarize an expanded framework of Decision Support Systems and stimulate debate about how we explain and categorize various systems and technologies for supporting decision makers.

\section{Need for an Expanded Framework}

Decision Support Systems should be defined as a broad category of information systems for informing and supporting decision-makers. DSS are intended to improve and speed-up the processes by which people make and communicate decisions. We need to improve how we define Decision Support Systems on both a conceptual level and on a concrete, technical level. Both managers and DSS designers need to understand categories of decision support so they can better communicate about what needs to be accomplished in informing and supporting decision makers.

The DSS literature includes a number of frameworks for categorizing systems. Steven Alter (1980) developed the broadest and most comprehensive one more than 20 years ago. A new, broader typology or framework than Alter's (1980) is needed because Decision Support Systems are much more common and more diverse than when he conducted his research and proposed his framework. One of the long-standing conclusions from reading DSS case studies is that what managers, vendors and consultants call DSS can "take on many different forms and can be used in many different ways (Alter, 1980, p. 71)." Decision Support Systems do vary in many ways. Some DSS focus on data, some on models and some on communications. DSS also differ in scope, some DSS are intended for one "primary" user and used "stand-alone" for analysis and others are intended for many users in an organization.

In 1980, Steven Alter (pps. 73-93) proposed his taxonomy of Decision Support Systems. Alter's seven category typology is still relevant for discussing some types of DSS, but not for all DSS. Alter's idea was that a Decision Support System could be categorized in terms of the generic operations it performs, independent of type of problem, functional area or decision perspective. His seven types included: file drawer systems, data analysis systems, analysis information systems, accounting and financial models, representational models, optimization models, and suggestion models.

To keep the number of categories in a new framework manageable, one can and should consolidate Alter's typology into three broader types of Decision Support Systems.
For a number of years, Alter's first three types of DSS have been called data-oriented or data-driven; the second three types have been called model-oriented or modeldriven; and Alter's suggestion DSS type has been called intelligent or knowledge-driven DSS (cf., Dhar and Stein, 1997; Holsapple and Whinston, 1996). The goal in proposing this expanded DSS framework is to help people understand how to integrate, evaluate and select appropriate means for supporting and informing decision-makers.

\section{An Expanded Framework}

The following expanded DSS framework is still evolving. The author and others have used the framework to classify a large number of software packages and systems. Anecdotal reports indicate that people who have tried to use it in describing a proposed or existing DSS have found it comprehensive, useful and parsimonious. It seems to help one categorize the most common Decision Support Systems currently in use. The framework focuses on one major dimension with 5 generic types of DSS and 3 secondary dimensions. The primary dimension is the dominant technology component or driver of the decision support system; the secondary dimensions are the targeted users, the specific purpose of the system and the primary deployment technology. Some DSS are best classified as hybrid systems driven by more than one major DSS component.

\section{Data-Driven DSS}

The first generic type of Decision Support System is a Data-Driven DSS. These systems include file drawer and management reporting systems, data warehousing and analysis systems, Executive Information Systems (EIS) and Spatial Decision Support Systems. Business Intelligence Systems are also examples of Data-Driven DSS. DataDriven DSS emphasize access to and manipulation of large databases of structured data and especially a time-series of internal company data and sometimes external data. Simple file systems accessed by query and retrieval tools provide the most elementary level of functionality. Data warehouse systems that allow the manipulation of data by computerized tools tailored to a specific task and setting or by more general tools and operators provide additional functionality. Data-Driven DSS with Online Analytical Processing (OLAP) provide the highest level of functionality and decision support that is linked to analysis of large collections of historical data (cf., Dhar and Stein, 1997). Professor Paul Gray argues that in approximately 1993, "the data warehouse and the EIS people found one another, 
with the data warehouses obtaining their needed application and the EIS people receiving a new breath of life from expanding beyond the pretty screen."

\section{Model-Driven DSS}

A second category, Model-Driven DSS, includes systems that use accounting and financial models, representational models, and optimization models. Model-Driven DSS emphasize access to and manipulation of a model. Simple statistical and analytical tools provide the most elementary level of functionality. Some OLAP systems that allow complex analysis of data may be classified as hybrid DSS systems providing modeling, data retrieval and data summarization functionality. Model-Driven DSS use data and parameters provided by decision-makers to aid them in analyzing a situation, but they are not usually data intensive. Very large databases are usually not needed for Model-Driven DSS.

\section{Knowledge-Driven DSS}

The terminology for this third generic type of DSS is still evolving. Currently, the best term seems to be KnowledgeDriven DSS. Sometimes it seems equally appropriate to use Alter's original term, Suggestion DSS, or the narrower term Management Expert System. Adding the modifier "driven" to the word knowledge maintains a parallelism in the framework and focuses on the dominant knowledge base component. Knowledge-Driven DSS can suggest or recommend actions to managers. These DSS are personcomputer systems with specialized problem-solving expertise. The "expertise" consists of knowledge about a particular domain, understanding of problems within that domain, and "skill" at solving some of these problems. A related concept is Data Mining. It refers to a class of analytical applications that search for hidden patterns in a database. Data mining is the process of sifting through large amounts of data to produce data content relationships. Tools used for building Knowledge-Driven DSS are sometimes called Intelligent Decision Support methods (cf., Dhar and Stein, 1997). Data Mining tools can be used to create hybrid DSS that have major data and knowledge components.

\section{Document-Driven DSS}

A new type of DSS, a Document-Driven DSS or Knowledge Management System, is evolving to help managers retrieve and manage unstructured documents and Web pages. A Document-Driven DSS integrates a variety of storage and processing technologies to provide complete document retrieval and analysis. The Web provides access to large document databases including databases of hypertext documents, images, sounds and video. Examples of documents that would be accessed by a Document-Based DSS are policies and procedures, product specifications, catalogs, and corporate historical documents, including minutes of meetings, corporate records, and important correspondence. A search engine is a powerful decisionaiding tool associated with a Document-Driven DSS (cf., Fedorowicz, 1993, pp. 125-136).

\section{Communications-Driven and Group DSS}

Group Decision Support Systems (GDSS) came first, but now a broader category of Communications-Driven DSS or groupware can be identified. This fifth generic type of Decision Support System includes communication, collaboration and decision support technologies that do not fit within those DSS types identified by Alter. Therefore, we need to identify these systems as a specific category of DSS. A Group DSS is a hybrid Decision Support System that emphasizes both the use of communications and decision models. A Group Decision Support System is an interactive computer-based system intended to facilitate the solution of problems by decision-makers working together as a group. Groupware supports electronic communication, scheduling, document sharing, and other group productivity and decision support enhancing activities. We have a number of technologies and capabilities in this category in the framework - Group DSS, two-way interactive video, White Boards, Bulletin Boards, and Email.

\section{Inter-Organizational or Intra-Organizational DSS}

A relatively new targeted user group for DSS made possible by new technologies and the rapid growth of the Internet is customers and suppliers. We can call DSS targeted for external users an Inter-Organizational DSS. The public Internet is creating communication links for many types of inter-organizational systems, including DSS. An Inter-Organizational DSS provides stakeholders with access to a company's intranet and authority or privileges to use specific DSS capabilities. Companies can make a Data-Driven DSS available to suppliers or a Model-Driven DSS available to customers to design a product or choose a product. Most DSS are Intra-Organizational DSS that are designed for use by individuals in a company as "standalone DSS" or for use by a group of managers in a company as a Group or Enterprise-Wide DSS. The prefix 


\section{Supporting Decision-Makers}

"intra" means the DSS is used within a specific organization and "inter" means the DSS is used more widely.

\section{Function-Specific or General Purpose DSS}

Many DSS are designed to support specific business functions or types of businesses and industries. We can call such a Decision Support System a function-specific or industry-specific DSS. A Function-Specific DSS like a budgeting system may be purchased from a vendor or customized in-house using a more general-purpose development package. Vendor developed or "off-the-shelf" DSS support functional areas of a business like marketing or finance; some DSS products are designed to support decision tasks in a specific industry like a crew scheduling DSS for an airline. A task-specific DSS has an important purpose in solving a routine or recurring decision task.

Function or task-specific DSS can be further classified and understood in terms of the dominant DSS component, that is as a Model-Driven, Data-Driven or Suggestion DSS. A function or task-specific DSS holds and derives knowledge relevant for a decision about some function that an organization performs (e.g., a marketing function or a production function). This type of DSS is categorized by purpose; function-specific DSS help a person or group accomplish a specific decision task. General-purpose DSS software helps support broad tasks like project management, decision analysis, or business planning. The most general purpose Decision Support Systems are sometimes called DSS generators because they can be used to develop or "generate" more specific DSS (cf., Sprague and Carlson, 1982).

\section{Web-Based DSS}

Finally, the deployment technology may be a mainframe computer, a client/server LAN, or a Web-Based architecture. All of the above generic types of DSS can be deployed using Web technologies and we can call these systems Web-Based DSS. A Web-Based DSS is a computerized system that delivers decision support information or decision support tools to a manager or business analyst using a "thin-client" Web browser like Netscape Navigator or Internet Explorer. The computer server that is hosting the DSS application is linked to the user's computer by a network with the TCP/IP protocol. In many companies, a Web-Based DSS is synonymous with an intranet or Enterprise-Wide DSS. A company intranet is supporting a large group of managers using Web browsers in a networked environment (Power, 1998). Managers increasingly have Web access to a data warehouse and analytical tools. Also, Web technologies are the primary tools used to create Inter-Organizational DSS that support the decision-making of customers and suppliers.

Web or Internet technologies are the leading edge for building DSS, but some Intra-Organizational DSS will continue to be built using traditional programming languages, fourth generation languages, "thick-client" application development tools, or mainframe enabling technologies.

Table 1 is a summary of this multi-attribute DSS classification framework. The far left column lists the five generic categories of Decision Support Systems that differ in terms of the dominant DSS technology component, including Communications-Driven DSS, Data-Driven DSS, Document-Driven DSS, Knowledge-Driven DSS and ModelDriven DSS. The next three columns provide examples of the secondary attributes: target users, purpose and deployment technology.

When the target users are customers and other external users the label inter-organizational seems an appropriate descriptor. When all of the users are internal to the company that "owns" the DSS, then intra-organizational serves as a descriptor. Also as noted, Decision Support Systems can be categorized by the purpose of the DSS. Many DSS have a narrow, focused, specific purpose rather than a general purpose. Finally, DSS can be described by the basic deployment technology. The Web is an important new development arena for DSS so it is crucial to examine and understand Web-Based DSS. We can use dominant DSS component, target users, purpose and deployment technology to categorize a specific system. For example, we may want to build a Model-Driven, Inter-Organizational, Product Design, Web-Based DSS. 


\begin{tabular}{|l|l|l|l|}
\hline $\begin{array}{l}\text { Dominant DSS } \\
\text { Component }\end{array}$ & $\begin{array}{l}\text { Target Users: } \\
\text { Internal } \rightarrow \text { External }\end{array}$ & $\begin{array}{l}\text { Purpose: } \\
\text { General } \rightarrow \text { Specific }\end{array}$ & $\begin{array}{l}\text { Deployment } \\
\text { Technology }\end{array}$ \\
\hline $\begin{array}{l}\text { Communications } \\
\text { Communications- } \\
\text { Driven DSS }\end{array}$ & $\begin{array}{l}\text { Internal teams, now } \\
\text { expanding to exter- } \\
\text { nal partners }\end{array}$ & $\begin{array}{l}\text { Conduct a meeting or } \\
\text { Help users collaborate }\end{array}$ & $\begin{array}{l}\text { Web or Client/ } \\
\text { Server }\end{array}$ \\
\hline $\begin{array}{l}\text { Database } \\
\text { Data-Driven DSS }\end{array}$ & $\begin{array}{l}\text { Managers, staff, now } \\
\text { suppliers }\end{array}$ & $\begin{array}{l}\text { Query a Data Ware- } \\
\text { house }\end{array}$ & $\begin{array}{l}\text { Main Frame, Cli- } \\
\text { ent/Server, Web }\end{array}$ \\
\hline $\begin{array}{l}\text { Document base } \\
\text { Document-Driven } \\
\text { DSS }\end{array}$ & $\begin{array}{l}\text { Internal users, but } \\
\text { the user group is ex- } \\
\text { panding }\end{array}$ & $\begin{array}{l}\text { Search Web pages or } \\
\text { Find documents }\end{array}$ & $\begin{array}{l}\text { Web or Client/ } \\
\text { Server }\end{array}$ \\
\hline $\begin{array}{l}\text { Knowledge base } \\
\text { Knowledge- } \\
\text { Driven DSS }\end{array}$ & $\begin{array}{l}\text { Internal users, now } \\
\text { customers }\end{array}$ & $\begin{array}{l}\text { Management Advice } \\
\text { or Choose products }\end{array}$ & $\begin{array}{l}\text { Client/Server, Web, } \\
\text { Stand-alone PC }\end{array}$ \\
\hline $\begin{array}{l}\text { Models } \\
\text { Model-Driven } \\
\text { DSS }\end{array}$ & $\begin{array}{l}\text { Managers and staff, } \\
\text { now customers }\end{array}$ & $\begin{array}{l}\text { Crew Scheduling or } \\
\text { Decision Analysis }\end{array}$ & $\begin{array}{l}\text { Stand-alone PC or } \\
\text { Client/Server or Web }\end{array}$ \\
\hline
\end{tabular}

Table 1. An Expanded DSS Framework.

\section{DSS Components}

Traditionally, academics and MIS staff have discussed building Decision Support Systems in terms of four major components - 1) the user interface, 2) the database, 3) the models and analytical tools, and 4) the DSS architecture and network (cf., Sprague and Carlson, 1982). This traditional list of components remains useful because it identifies similarities and differences between categories or types of DSS. The DSS framework is primarily based on the different emphases placed on DSS components when systems are actually constructed.

Data-Driven, Document-Driven and Knowledge-Driven DSS need specialized database components. A ModelDriven DSS may use a simple flat-file database with fewer than 1,000 records, but the model component is very important. Experience and some empirical evidence indicate that design and implementation issues vary for Data-
Driven, Document-Driven, Model-Driven and KnowledgeDriven DSS. Multi-participant systems like Group and Inter-Organizational DSS also create complex implementation issues. For instance, when implementing a Data-Driven DSS a designer should be especially concerned about the user's interest in applying the DSS in unanticipated or novel situations. Despite the significant differences created by the specific task and scope of a DSS, all Decision Support Systems have similar technical components and share a common purpose, supporting decision-making.

A Data-Driven DSS database is a collection of current and historical structured data from a number of sources that have been organized for easy access and analysis. We are expanding the data component to include unstructured documents in Document-Driven DSS and "knowledge" in the form of rules or frames in Knowledge-Driven DSS. Supporting management decision-making means that com- 


\section{Supporting Decision-Makers}

puterized tools are used to make sense of the structured data or documents in a database.

Mathematical and analytical models are the major component of a Model-Driven DSS. Each Model-Driven DSS has a specific set of purposes and hence different models are needed and used. Choosing appropriate models is a key design issue. Also, the software used for creating specific models needs to manage needed data and the user interface. In Model-Driven DSS the values of key variables or parameters are changed, often repeatedly, to reflect potential changes in supply, production, the economy, sales, the marketplace, costs, and/or other environmental and internal factors. Information from the models is then analyzed and evaluated by the decision-maker. Knowledge-Driven DSS use special models for processing rules or identifying relationships in data.

The DSS architecture and networking design component refers to how hardware is organized, how software and data are distributed in the system, and how components of the system are integrated and connected. A major issue today is whether DSS should be available using a Web browser on a company intranet and also available on the Global Internet. Networking is the key driver of Communications-Driven DSS.

\section{Conclusions}

The field of Decision Support Systems has in many way suffered from the broad use of the term DSS. Informing and communicating involve using shared concepts. Every Decision Support System is not the same and both researchers and managers need a meaningful framework for discussing what is being done to support decision-making using information technologies. This paper sets out a framework for labeling and categorizing systems intended to support decision-making. A specific Decision Support System should be discussed and explained in terms of four descriptors: the dominant technology component or components, the targeted users, the specific purpose of the system and the primary deployment technology.

\section{References}

Alter, S.L. (1990) Decision Support Systems: Current Practice and Continuing Challenge. Reading, MA: Addison-Wesley.

Dhar, V. and R. Stein (1997). Intelligent Decision Support Methods: The Science of Knowledge. Upper Saddle River, NJ: Prentice-Hall.

Fedorowicz, J. (1993) "A Technology Infrastructure for DocumentBased Decision Support Systems", in Sprague, R. and H. J. Wat- son, Decision Support Systems: Putting Theory into Practice (Third Edition), Prentice-Hall, pp. 125-136.

Holsapple, C.W. and A. B. Whinston (1996) Decision Support Systems: A Knowledge-based Approach. Minneapolis, MN: West Publishing Co.

Power, D. J. "What is a DSS?" DS*Star, The On-Line Executive Journal for Data-Intensive Decision Support, October 21, 1997: Vol. 1, No. 3. URL http://dssresources.com/papers/whatisadss

Power, D. J. " Web-based Decision Support Systems". DS*Star, The On-Line Executive Journal for Data-Intensive Decision Support, August 18 and 25, 1998: Vol. 2, Nos. 33 and 34. (URL http://dssresources.com/papers/webdss

Scott Morton, Michael S. (1971) Management Decision Systems: Computer-based Support for Decision Making. Boston, MA: Division of Research, Graduate School of Business Administration, Harvard University.

Sprague, R.H. and E.D. Carlson (1982). Building Effective Decision Support Systems. Englewood Cliffs, NJ: Prentice-Hall.

Sprague, R. H. and Hugh J. Watson (editors) (1996). Decision Support for Management. Englewood Cliffs, N.J.: Prentice-Hall, Inc.

\section{Biography}

Daniel J. Power is a Professor of Information Systems and Management at the College of Business Administration at the University of Northern Iowa, Cedar Falls, Iowa.

Dr. Power's research interests include the design and development of Decision Support Systems and how DSS impact individual and organizational decision behavior. He is also a developer of computerized decision aiding software.

Since 1982, Daniel Power has published more than 40 articles, book chapters and proceedings papers. Professor Power is the editor of the World-Wide Web site DSSResources.COM at URL http://DSSResources.COM.

In 1982, Professor Power received a Ph.D. in Business Administration from the University of Wisconsin-Madison. He was on the faculty at the University of MarylandCollege Park from 1982 to 1989. Also, he has been a visiting lecturer at universities in China, Denmark, Ireland, Israel, and Russia.

In 1981-83 Professor Power programmed a computerized decision aid called DECAID for the Apple II. In 1986-87 he designed and developed software decision tools for the Southwestern Management Decision Assistant. 